\title{
Atmospheric circulation as a source of uncertainty in climate change projections
}

Article

Accepted Version

Author final version

Shepherd, T.G. (2014) Atmospheric circulation as a source of uncertainty in climate change projections. Nature Geoscience, 7. pp. 703-708. ISSN 1752-0894 doi:

https://doi.org/10.1038/ngeo2253 Available at https://centaur.reading.ac.uk/37752/

It is advisable to refer to the publisher's version if you intend to cite from the work. See Guidance on citing.

To link to this article DOI: http://dx.doi.org/10.1038/ngeo2253

Publisher: Nature Publishing Group

All outputs in CentAUR are protected by Intellectual Property Rights law, including copyright law. Copyright and IPR is retained by the creators or other copyright holders. Terms and conditions for use of this material are defined in the End User Agreement.

\section{www.reading.ac.uk/centaur}

\section{CentAUR}

Central Archive at the University of Reading

Reading's research outputs online 
Atmospheric circulation as a source of uncertainty in climate change projections

Theodore G. Shepherd

Department of Meteorology, University of Reading, Reading RG6 6BB, U.K.

As the evidence for anthropogenic climate change continues to strengthen and concerns about severe weather events increase, scientific interest is rapidly shifting from detection and attribution of global climate change to prediction of its impacts at the regional scale. However, pretty much everything we have any confidence in when it comes to climate change is related to global patterns of surface temperature, which are primarily controlled by thermodynamics. In contrast, we have much less confidence in circulation aspects of climate change, which are primarily controlled by dynamics and which exert a strong control on regional climate. Model projections of circulation-related fields (including precipitation) show a wide range of possible outcomes, even on centennial timescales. Sources of uncertainty include low-frequency chaotic variability and the sensitivity to model error of the circulation response to climate forcing. Because the circulation response to external forcing appears to project strongly onto the patterns of variability, knowledge of errors in the dynamics of variability may provide constraints on the model projections. Nevertheless, because of these uncertainties, higher scientific confidence in circulation-related aspects of climate change will be difficult to obtain and for effective decision-making it is necessary to move to a more explicitly probabilistic, risk-based approach.

The accepted evidence of anthropogenic climate change ${ }^{1}$ is based on multiple global indicators of change including surface temperature, upper-ocean heat content, sea level, Arctic sea-ice extent, glaciers, Northern Hemisphere snow cover, large-scale precipitation patterns (especially as reflected in ocean salinity), and temperature extremes (Figure 1a,b). All these global indicators are physically linked in a direct way to the first on the list, surface temperature, and the changes are robust in observations, theory, and models ${ }^{1}$. Because of the consistency of the evidence and the physical understanding of the changes, both scientific and public attention is rapidly shifting from the detection and attribution of global climate change - by all measures a settled scientific question - to the quantification and prediction of its manifestations at the regional scale, together with an increasing demand for uncertainties. This attention is heightened whenever there are record-breaking weather events, recent examples being Australian summertime heat waves, wintertime cold-air outbreaks over the continental US, and wintertime flooding in the UK. Although the proximate explanation of such events is always the synoptic weather patterns prevailing at the time, the inevitable question that arises is whether such events are now more likely and are harbingers of things to come'2.

On the regional scale, climate is strongly affected by aspects of the atmospheric circulation such as monsoons, jet streams and storm tracks. For example, there is a 
well-documented relationship between the North Atlantic Oscillation, with its associated modulation of the position of the North Atlantic storm track, and wintertime weather conditions over Europe ${ }^{3}$. More generally there is a relationship between the amplitude of mid-latitude planetary waves and particular regional weather extremes, which varies with region and implies that opposite-signed extremes in different regions may reflect the same underlying driver 4 . Planetary waves also provide non-local teleconnections, e.g. between El Niño-Southern Oscillation (ENSO) and the Indian summer monsoon ${ }^{5}$. Circulation furthermore impacts atmospheric chemistry; for example the observed changes in tropospheric ozone at Mauna Loa over the past 40 years have been attributed to changes in circulation rather than to changes in precursor emissions ${ }^{6}$. In contrast to the temperature-related global indicators mentioned earlier, circulation-related changes in climate are not robust in observations, theory, or models, leading to low confidence in their past or predicted changes ${ }^{1}$ as well as in those of circulationrelated impacts such as droughts and flooding7. Observational records of circulation-related quantities typically exhibit large variability on multi-decadal timescales, obscuring possible systematic changes (Figure 1c,d). Climate models are much less consistent in their predicted changes in precipitation than in temperature (Figure 2) ${ }^{8}$; since precipitation is controlled by both temperature and circulation, the implication is that the inconsistencies arise from circulation. The weak theoretical understanding of circulation aspects of climate change is reflected in their characterization by empirical indices whose physical basis is often unclear, and by the lack of consensus on the mechanisms driving hypothesized circulation changes ${ }^{1}$.

There are two fundamental principles of physics represented in climate models: the first law of thermodynamics, and dynamics (Newton's second law, or $F=m a$ ). Every aspect of climate change in which there is strong confidence, including not only the surface-temperature related quantities mentioned above but also certain globalscale patterns (e.g. land-sea contrast, weakened tropical overturning), is based on thermodynamics. Circulation, on the other hand, is also governed by dynamics. Therefore the earlier dichotomy can be re-stated as saying there is relatively high confidence in the thermodynamic aspects of climate change, and relatively low confidence in the dynamic aspects. As noted above, precipitation is under both thermodynamic and dynamic control. Statements of confidence concerning precipitation changes are based on thermodynamics, but models suggest that on the regional scale, dynamic controls on precipitation can be very strong - leading to large uncertainty such as seen in Figure 2.

The different levels of understanding of the thermodynamic and dynamic responses to climate change reflects the different nature of those responses. Changes in radiative forcing, such as from increased greenhouse gases, directly perturb the thermodynamic balance of the climate system and the first-order response is a change in atmospheric temperature and associated quantities such as humidity. Moreover this response typically has a distinct fingerprint from that arising from internal variability ${ }^{9}$. The dynamic response is more indirect. Outside the tropics, the 
dynamic balance between eddy momentum fluxes in the free atmosphere and

2 boundary-layer friction provides a strong constraint on circulation ${ }^{10}$, which is not

3 directly impacted by radiative forcing. The dominant circulation response to

4 changes in radiative forcing thus occurs indirectly, through eddy feedbacks, and projects strongly onto the patterns of internal variability ${ }^{11,12}$. This makes it difficult to distinguish from internal variability through fingerprinting techniques. Although tropical circulation is generally regarded as being thermodynamically controlled ${ }^{13}$, the diabatic heating that is in balance with the vertical motion is dependent on convective fluxes of heat and moisture (which in climate models must be parameterized), and these in turn depend on the large-scale circulation (including the rotational component, which satisfies a dynamic balance ${ }^{13}$ ) and its coupling to surface conditions. Thus, dynamics enters strongly into the thermodynamic balance. This is illustrated by the modelled tropical precipitation response to global warming, which on the regional scale can depart significantly from the "wet-getwetter, dry-get-drier" pattern expected from thermodynamics, because of the circulation response $\mathrm{e}^{14,15}$.

\section{The nature of the problem}

\section{Role of natural variability}

In physics, nonlinear dynamics generically leads to chaos ${ }^{16}$, meaning behaviour that is non-periodic in time and predictable only for limited times. The climate system is chaotic in much the same way due to its nonlinear internal dynamics ${ }^{17}$. In contrast to externally forced natural variability, e.g. from solar variations or volcanic eruptions, such internally generated variability is generally not characterized by well-defined timescales and thus cannot be completely eliminated by time averaging ${ }^{18}$. Whether climate change dominates over the variability for a given time horizon depends very much on the field in question. Figure 1 illustrates that climate change dominates on multi-decadal timescales for global-scale temperature-related fields, but not for circulation-related fields. The latter can show apparent multidecadal trends that are subsequently reversed, suggesting that such trends are dominated by internal variability. For example, the observed decrease in drought severity over the central United States during the second half of the $20^{\text {th }}$ century is opposite to the change expected from global warming and appears to have been mainly driven by variability associated with tropical sea-surface temperatures ${ }^{19}$.

Quantitative estimates of the role of natural variability can be provided by climate models ${ }^{20}$. An ensemble of projections generated by the same model, starting from randomly chosen initial conditions but subject to the same external forcing, will quickly diverge due to chaos and will sample the universe of possible realizations of the climate system under those external forcings, of which the observed system represents but one. Figure 3 shows such a calculation for wintertime changes over a 55-year period in the Eurasian-North Atlantic sector. The distribution of possible changes in surface temperature is seen to be distinct from that in the control ensemble with no climate change. This means that climate change will be detectable, and the long-term change almost inevitably one of warming, even for single 
realizations - such as in the real climate system. However the situation for both precipitation and surface pressure (a measure of circulation) is markedly different; whilst the distributions of the two ensembles are statistically distinct, they are strongly overlapping, meaning that climate change would not be reliably detectable from a single realization ${ }^{20}$. Indeed there is a reasonable likelihood (roughly 30\%) that the long-term change from a single realization would be opposite in sign to the anthropogenic signal (the mean of the climate-change distribution).

When one considers climate change on the regional scale, and especially its circulation-related aspects (including precipitation), this sort of situation seems likely to be the rule, and robust predictions the exception. Figure 2 shows large parts of the globe where even for a strong warming scenario (RCP 8.5), and a 100year time horizon, the precipitation changes lie within the natural variability (indicated by hatching). For shorter time horizons the regions of hatching increase, covering practically the entire globe for 30-year projections ${ }^{8,1}$. And even surface temperature can show large variability when considered over particular seasons and regions ${ }^{21}$. The regional coherence of this circulation-related variability has implications for climate impacts ${ }^{21}$. According to the IPCC's confidence language ${ }^{1}$, a $30 \%$ possibility is regarded as "unlikely", and one might naively regard a change lying within natural variability as inconsequential. However, the impact of climate change on the distribution of possible 55-year trends in precipitation shown in Figure 3 is quite large, roughly a factor of two, for the upper and lower thirds of the distribution. Although there is inherently low confidence in any single prediction, and one cannot expect the observed behaviour to be a robust indicator of climate change, there is a significant change in risk related to extremes ${ }^{22}$.

\section{Role of model error}

Climate models are, of course, imperfect representations of the real climate system. Differences between models and observations that are not attributable either to natural variability, to errors in forcings, or to representativeness issues can be considered to be model error. Models may exhibit errors in their climatologies (time-averaged states), statistical relationships between different fields, or the characteristics of their natural variability. Differences in model projections under the same forcing scenario that are not attributable to natural variability represent model uncertainty, and increasingly dominate over differences due to natural variability as the time horizon increases ${ }^{23}$. Although the concept of model error is not well-defined in the case of projections because the truth is not known, it seems reasonable to suppose that model error in one form or another must underlie model uncertainty.

There is abundant evidence for the impact of model differences on projections of circulation-related aspects of climate. Most of the model spread in projected changes in tropical precipitation comes from the large-scale circulation, and appears to be related to the fast response to increased greenhouse gases which is clearly sensitive to model error ${ }^{14}$. Modelled ENSO variability is sensitive to the ocean climatology ${ }^{24}$. Model errors in tropical sea-surface temperature furthermore affect 
regional patterns of climate change in the extratropics ${ }^{19}$. Within the extratropics, the response to Pacific sea-surface temperature anomalies is sensitive to model climatology 25 . The northern high-latitude wintertime surface pressure response to climate change, and movement of the North Atlantic jet, is sensitive to the state of the polar stratosphere ${ }^{26,27}$. On the other hand, the response of the wintertime North Atlantic jet to changes in the stratosphere is sensitive to the location of the jet ${ }^{28}$. This stratosphere-troposphere coupling may be part of the reason for the qualitatively different changes in near-surface winds over the North Atlantic from four CMIP5 models (Figure 4). In all these cases, even the sign of the climate-change response can be uncertain on the regional scale.

In Figure 2, regions where the climate-change signal is robust, meaning most models agree on the sign of the change, are indicated with stippling. By this definition (which still allows for significant quantitative differences), the temperature changes (for this forcing scenario and time horizon) are robust everywhere. However, the precipitation changes are robust mainly at high latitudes. Although much of the nonrobustness is attributable to natural variability - the hatching attempts to indicate where this is likely to be the case - much likely reflects systematic discrepancies between models and is thus linked in some way to model error. The robustness of climate model projections has changed little in recent years ${ }^{8}$, suggesting that the underlying model errors are stubborn. The most uncertain aspect of climate modelling lies in the representation of unresolved (subgridscale) processes such as clouds, convection, and boundary-layer and gravity-wave drag, and its sensitive interaction with large-scale dynamics $29,30,31$. It is therefore reasonable to hypothesize that the representation of these processes is responsible for systematic non-robustness of the predicted circulation response to climate change.

\section{Connection between model error and variability}

We have seen that precipitation is not only more variable than temperature, relative to the expected response to climate change, but its response to climate change appears to be less robust. There are reasons to believe that these two properties may be related. In statistical physics, the fluctuation-dissipation theorem (FDT) ${ }^{32}$ relates the response of a system to an applied perturbation to the intrinsic timescales of its internal modes of variability, with the longer-timescale modes responding more strongly. To consider the simplest possible example, the response of a damped spring to an applied force is greater for a slacker spring, with a longer period of oscillation. Note that although the FDT predicts the linear response of a system, it is not restricted to linear systems, only to small perturbations. An important implication of the FDT is that the response to an external perturbation can be expected to project, perhaps strongly, on the internal modes of variability just as is seen in climate models ${ }^{11}$. In such cases it will be very difficult to separate signal from noise using purely statistical methods.

The potential relevance of the FDT to atmospheric circulation can be illustrated by the example of latitudinal variations in the position of the mid-latitude jet. This socalled 'annular-mode' variability occurs naturally in both observations and models, 


\section{4}

induced by random fluctuations in weather systems and reinforced by a positive eddy feedback which acts against surface friction ${ }^{33}$. The timescale of the annularmode variability is determined by the strength of the restoring force, which represents the difference between frictional damping and the positive eddy feedback: the weaker the restoring force, the longer the timescale ${ }^{33}$. This is analogous to a slacker spring having a longer period of oscillation. When an external forcing is applied, this perturbs the jet which induces the same eddy feedbacks as occur from natural variability, and the perturbation acts against the same restoring force. Thus, the same internal feedbacks that govern the natural variability of the jet also govern its response to forcing, and a larger response to a given forcing is expected to occur for a weaker restoring force. Such a relationship for the midlatitude jet is indeed found in idealized experiments ${ }^{28,33}$.

If the FDT could be reliably applied to the problem of climate change, then it would provide a theoretical framework for understanding such important questions as the effect of model error on predicted changes, and the demonstrated sensitivity of the circulation response to the spatial structure of the forcing12,34,35. The apparently linear response of extratropical atmospheric stationary waves to tropical seasurface temperature perturbations ${ }^{19,36}$ lends plausibility to the notion that the FDT may be relevant. Unfortunately, whether and how the FDT can be applied to the climate system remains open. The theorem can be derived from different assumptions ${ }^{37}$ and may therefore be rather general. However, the climate system is not in equilibrium and what appear to be internal timescales may themselves reflect a response to forcing 38,39 . One intriguing study ${ }^{40}$ found that the FDT predicted the annular-mode response to external forcings in a qualitative but not quantitative manner, in that the magnitude of the response differed between mechanical and thermal forcing, and in neither case was consistent with the annular-mode timescale.

Of course, the framework of the FDT may be too limiting; nonlinear systems can respond to an external forcing through a change in occupancy of preferred states ${ }^{41}$, as well as through quasi-linear shifts in the patterns of variability ${ }^{36}$. Nevertheless the broader concept that the circulation response to forcing is related to the variability of the system seems well grounded. In which case, errors in one should be related in some way to errors in the other.

\section{The way ahead}

The importance of natural variability for near-term climate projections means that projections must be probabilistic in nature ${ }^{21}$. In the case of Figure 3, the lack of confidence in any single predicted outcome for precipitation need not preclude a probabilistic, risk-based assessment, which would be (assuming no model error) that while the risk of higher-than-average wintertime precipitation is increased by something like a factor of two over the 55-year period, lower-than-average wintertime precipitation cannot be excluded. The limited observational record implies that estimates of variability must mainly come from models. Unfortunately climate models tend to exhibit a wide range of low-frequency variability, especially 
for key aspects of regional climate such as Atlantic sea-surface temperatures and

2 ENSO teleconnections outside the tropical Pacific ${ }^{1}$. There is evidence that the CMIP5

3 models overall do not show enough variability in their past regional temperature

4 and precipitation trends, hence their ensemble forecasts are not reliable in a probabilistic sense ${ }^{42}$. However a purely statistical comparison between models and observations may reflect sampling errors because of the short observational record ${ }^{43}$. All this highlights the importance of identifying the physical mechanisms behind climate variability, rather than characterizing variability purely empirically as is generally the current practice ${ }^{1}$ (ENSO being the notable exception). This in turn highlights the importance of understanding current climate, as distinct from climate change, and the relationship between circulation anomalies and weather extremes. Seasonal prediction offers a useful framework for such efforts.

The divergence of model projections that arises from model errors means that it is essential to work towards reducing those errors, which are presumably associated with inadequate parameterizations of unresolved processes. Some aspects of the circulation response to forcing, and its dependence on model parameterizations, are already evident in the 'fast' response (before the ocean has responded) and are thus identifiable on weather-forecast timescales ${ }^{14}$. Although feedback from large-scale eddy fluxes can confound the parameter sensitivity, systematic errors in parameterizations can be identified through short-term forecasts from observed states, exploiting the timescale separation between resolved and unresolved processes ${ }^{44}$. This - together with the association of extremes with weather events - highlights the importance of collaboration between the weather and climate communities, to help understand and reduce climate model errors associated with parameterized processes.

In the meantime it is necessary to work with ensembles of imperfect models. Such ensembles are often interpreted probabilistically ${ }^{1}$, but this is clearly inappropriate since each model outcome cannot be considered equally likely ${ }^{45}$. Somehow it will be necessary to assess the reliability of the predictions and design appropriately calibrated ensembles. Weather predictions can be calibrated from past forecasts, but this is clearly not possible for climate projections because the relevant timescales are much too long. It has been suggested ${ }^{46}$ that for some quantities, the spread in model projections can be calibrated by the seasonal cycle. (More generally, the calibration can come from internal variability, or even from past (paleoclimate) forced responses.) This relies on the processes controlling the climate-change response being the same as those controlling the seasonal cycle, so a robust physical understanding is required to ensure that any relationship inferred from models is not merely circumstantial. It is worth noting that the two most cited examples of this approach ${ }^{46,47}$ are based on thermodynamics. This once again highlights the importance of developing a better physical understanding of the circulation response to climate change, based on hierarchies of models and robust mechanisms. Although this paper has emphasized the uncertainties, there are some apparently robust circulation responses - e.g. over the Mediterranean (Fig. 2) - which have 
yet to be satisfactorily explained. It may be that fairly simple principles such as

2 thermodynamic arguments or linear stationary-wave theory can help in some cases.

3 The role of circulation in many aspects of climate change has profound implications

4 for how climate change is discussed. For thermodynamic aspects of climate, the

5 observational record speaks for itself and confident statements about future projections are possible. Yet these statements, especially for precipitation-related extremes such as droughts and flooding, may not be very useful on the regional scale $^{48,49}$ because of the role of circulation, for which the observational record is ambiguous and confident statements about future projections are not forthcoming. The reasons for this are fundamental and are unlikely to change any time soon. Yet the potential change in weather-related risk associated with circulation aspects of climate change may be considerable. In order to discuss climate change under these circumstances, it seems necessary to move from a confidence-based approach to a more explicitly probabilistic, risk-based approach.

\section{Methods}

In Figure 1, the global-mean surface temperature data is the HadCRUT4 anomaly dataset (referenced to 1961-1990) obtained from NOAA (http://www.esrl.noaa.gov/psd/data/gridded/), the Arctic summer (July through September) sea-ice extent data is an extended version of the dataset provided in Ref. 50 and available from NSIDC (http://nsidc.org/daac/users/), the Southern Oscillation Index data is the CRU dataset obtained from NOAA (http://www.esrl.noaa.gov/psd/data/gridded/), and the All-India Summer Monsoon Rainfall is the Indian Institute of Tropical Meteorology dataset obtained from IITM (http://www.tropmet.res.in/ kolli/MOL/Monsoon/Historical/air.html).

In Figure 4, winter refers to December through February and the differences are taken between 2070-2099 (RCP8.5 scenario) and 1976-2005 (historical simulations) for the four models indicated from the CMIP5 archive, available through PCMDI (http://pcmdi9.llnl.gov/esgf-web-fe/). Ensemble members r1i1p1 to $\mathrm{r} 5 \mathrm{i} 1 \mathrm{p} 1$ were used for all the models except EC-EARTH, where ensemble members r1i1p1, r2i1p1, r8i1p1, r9i1p1 and r12i1p1 were used. For each model, the statistical significance of the change was estimated from a student t-test on the 532 member ensemble.

\section{References}

34 1. Intergovernmental Panel on Climate Change, Climate Change 2013: The Physical 35 Science Basis. Contribution of Working Group I to the Fifth Assessment Report of the 36 Intergovernmental Panel on Climate Change (Stocker, T. F. et al., Eds.), Cambridge 37 University Press, Cambridge University Press, Cambridge, United Kingdom and New 38 York, NY, USA, 1535 pp. (IPCC, 2013).

39 2. The Recent Storms and Floods in the UK, briefing paper available from

40 http://www.metoffice.gov.uk/media/pdf/1/2/Recent Storms Briefing Final SLR 2 41 0140211.pdf (Met Office, 2014). 
3. Bühler, T., Raible, C. C. \& Stocker, T. F. The relationship of winter season North

2 Atlantic blocking frequencies to extreme cold or dry spells in the ERA-40. Tellus A,

$363,212-222$ (2011).

4 4. Screen, J. A. \& Simmonds, I. Amplified mid-latitude planetary waves favour

5 particular regional weather extremes. Nature Climate Change 4, 704-709 (2014).

6 5. Turner, A. G. \& Annamalai, H. Climate change and the South Asian summer

7 monsoon. Nature Climate Change 2, 587-595 (2012).

8 6. Lin, M., Horowitz, L. W., Oltmans, S. J., Fiore, A. M. \& Fan, S. Tropospheric ozone

9 trends at Mauna Loa Observatory tied to decadal climate variability. Nature Geosci.

10 7, 136-143 (2014).

7. Intergovernmental Panel on Climate Change, Managing the Risks of Extreme Events and Disasters to Advance Climate Change Adaptation. A Special Report of Working Groups I and II of the Intergovermental Panel on Climate Change (Field, C. B. et al., Eds.). Cambridge University Press, 582 pp. (IPCC, 2012).

8. Knutti, R. \& Sedlacek, J. Robustness and uncertainties in the new CMIP5 climate model projections. Nature Climate Change 3, 369-373 (2013).

18 9. Stott, P. A. et al. External control of 20th century temperature by natural and 19 anthropogenic forcings. Science 290, 2133-2137 (2000).

20 10. Hoskins, B. J. Theory of transient eddies. Large-Scale Dynamical Processes in the 21 Atmosphere (Hoskins, B. J. \& Pearce, R. P., Eds.). Academic Press, 169-199 (1983).

22 11. Deser, C., Magnusdottir, G., Saravanan, R. \& Phillips, A. The effects of North 23 Atlantic SST and Sea Ice anomalies on the winter circulation in CCM3. Part II: Direct 24 and indirect components of the response. J. Clim. 17, 877-889 (2004).

25 12. Simpson, I. R., Blackburn, M. \& Haigh, J. D. The role of eddies in driving the 26 tropospheric response to stratospheric heating perturbations. J. Atmos. Sci. 66,

27 1347-1365 (2009).

13. Held, I. M. \& Hoskins, B. J. Large-scale eddies and the general circulation of the 30 troposphere. Adv. Geophys. 28A, 3-31 (1985).

31 14. Bony, S. et al. Robust direct effect of carbon dioxide on tropical circulation and

32 regional precipitation. Nature Geosci. 6, 447-451 (2013).

33 15. Chadwick, R., Boutle, I. \& Martin, G. Spatial patterns of precipitation change in 34 CMIP5: Why the rich do not get richer in the tropics. J. Clim. 27, 3803-3822 (2013).

35 16. Strogatz, S. H. Nonlinear Dynamics and Chaos: With applications to physics, 36 biology, chemistry, and engineering. Perseus Books, 512 pp. (1994). 
1 17. Palmer, T. N. A nonlinear dynamical perspective on climate prediction. J. Clim.

2 12, 575-591 (1999).

3 18. Wunsch, C. The interpretation of short climate records, with comments on the

4 North Atlantic and Southern Oscillations. Bull. Amer. Meteor. Soc. 80, 245-255

5 (1999).

6 19. Shin S.-I. \& Sardeshmukh, P. D. Critical influence of the pattern of Tropical Ocean

7 warming on remote climate trends. Clim. Dyn. 36, 1577-1591 (2011).

8 20. Deser, C., Phillips, A., Bourdette, V. \& Teng, H. Y. Uncertainty in climate change

9 projections: the role of internal variability. Clim. Dyn., 38, 527-546 (2012).

10 21. Deser, C., Phillips, A. S., Alexander, M. A. \& Smoliak, B. V. Projecting North

11 American climate over the next 50 years: Uncertainty due to internal variability. $J$.

12 Clim. 27, 2271-2296 (2014).

13 22. Palmer, T. N. \& Räisänen, J. Quantifying the risk of extreme seasonal

14 precipitation events in a changing climate. Nature 415, 512-514 (2002).

15 23. Hawkins, E. \& Sutton, R. The potential to narrow uncertainty in projections of

16 regional precipitation change. Clim. Dyn. 37, 407-418 (2011).

17 24. Fedorov, A. V. \& Philander, S. G. A stability analysis of tropical ocean-atmosphere

18 interactions: Bridging measurements and theory for El Nino. J. Clim. 14, 3086-3101

19 (2001).

20

21 25. Hall, N. M. J., Derome, J. \& Lin, H. The extratropical signal generated by a

22 midlatitude SST anomaly. Part I: Sensitivity at equilibrium. J. Clim. 14, 2035-2053

23 (2001).

24 26. Sigmond, M. \& Scinocca, J. F. The influence of the basic state on the Northern

25 Hemisphere circulation response to climate change. J. Clim. 23, 1434-1446 (2010).

26 27. Scaife, A. A. et al. Climate change projections and stratosphere-troposphere

27 interaction. Clim. Dyn. 38, 2089-2097 (2012).

28 28. Garfinkel, C. I., Waugh, D. W. \& Gerber, E. P. The effect of tropospheric jet latitude 29 on coupling between the stratospheric polar vortex and the troposphere. J. Clim. 26, 30 2077-2095 (2013).

31 29. Chen, G., Held, I. M. \& Robinson, W. A. Sensitivity of the latitude of the surface 32 westerlies to surface friction. J. Atmos. Sci. 64, 2899-2915 (2007).

33 30. Stevens, B. \& Bony, S. What are climate models missing? Science 340, 1053-1054 34 (2013). 
1 31. Sandu, I., Beljaars, A., Bechtold, P., Mauritsen, T. \& Balsamo, G. Why is it so

2 difficult to represent stably stratified conditions in numerical weather prediction

3 (NWP) models? J. Adv. Model. Earth Syst. 5, 117-133 (2013).

4 32. Nyquist, H. Thermal agitation of electric charge in conductors. Phys. Rev. 32,

5 110-113 (1928).

6 33. Chen, G. \& Plumb, R. A. Quantifying the eddy feedback and the persistence of the

7 zonal index in an idealized atmospheric model. J. Atmos. Sci. 66, 3707-3720 (2009).

8 34. Son, S.-W. \& Lee, S. The response of westerly jets to thermal driving in a

9 primitive equation model. J. Atmos. Sci. 62, 3741-3757 (2005).

10 35. Tandon, N. F., Gerber, E. P., Sobel, A. H. \& Polvani, L. M. Understanding Hadley

11 Cell expansion versus contraction: Insights from simplified models and implications

12 for recent observations. J. Clim. 26, 4304-4321 (2013).

13 36. Branstator, G. \& Selten, F. "Modes of variability" and climate change. J. Clim. 22,

$14 \quad 2639-2658$ (2009).

15 37. Gritsun, A. \& Branstator, G. Climate response using a three-dimensional operator 16 based on the Fluctuation-Dissipation Theorem. J. Atmos. Sci. 64, 2558-2575 (2007).

17 38. Keeley, S. P. E., Sutton, R. T. \& Shaffrey, L. C. Does the North Atlantic Oscillation

18 show unusual persistence on intraseasonal timescales? Geophys. Res. Lett. 36,

19 L22706 (2009).

20 39. Simpson, I. R., Shepherd, T. G., Hitchcock, P. and Scinocca, J. F. Southern Annular

21 Mode dynamics in observations and models. Part 2: Eddy feedbacks. J. Clim. 26,

22 5220-5241 (2013).

23 40. Ring, M. J. \& Plumb, R. A. The response of a simplified GCM to axisymmetric

24 forcings: Applicability of the fluctuation-dissipation theorem. J. Atmos. Sci. 65, 3880-

253898 (2008).

26 41. Corti, S., Molteni, F. \& Palmer, T. N. Signature of recent climate change in

27 frequencies of natural atmospheric circulation regimes. Nature 398, 799-802

28 (1999).

29 42. van Oldenborgh, G. J., Doblas Reyes, F. J., Drijfhout, S. S. \& Hawkins, E. Reliability

30 of regional climate model trends. Env. Res. Lett., 8, 014055, doi: 10.1088/1748-

31 9326/8/1/014055 (2013).

32 43. Hitchcock, P., Shepherd, T. G. \& Manney, G. L. Statistical characterization of Arctic

33 Polar-night Jet Oscillation events. J. Clim. 26, 2096-2116 (2013).

34 44. McLandress, C., Shepherd, T. G., Polavarapu, S. \& Beagley, S. R. Is missing

35 orographic gravity wave drag near $60^{\circ} \mathrm{S}$ the cause of the stratospheric zonal wind

36 biases in chemistry-climate models? J. Atmos. Sci. 69, 802-818 (2012). 
1 45. Knutti, R., Masson, D. \& Gettelman, A. Climate model genealogy: Generation

2 CMIP5 and how we got there. Geophys. Res. Lett. 40, 1194-1199 (2013).

3 46. Hall, A. \& Qu, X. Using the current seasonal cycle to constrain snow albedo

4 feedback in future climate change. Geophys. Res. Lett. 33, L03502 (2006).

5 47. Cox, P. M. et al. Sensitivity of tropical carbon to climate change constrained by

6 carbon dioxide variability. Nature 494, 341-344 (2013).

7 48. Coughlan de Perez, E., Monasso, F., van Aalst, M. \& Suarez, P. Science to prevent

8 disasters. Nature Geosci. 7, 78-79 (2014).

9 49. Sandeep, S., Stordal, F., Sardeshmukh, P. D. \& Compo, G. Pacific Walker

10 Circulation variability in coupled and uncoupled climate models. Clim. Dyn. 43, 103-

11117 (2014).

12 50. Meier, W. N., Stroeve, J., Barrett, A. \& Fetterer, F. A simple approach to providing 13 a more consistent Arctic sea ice extent time series from the 1950s to present.

14 Cryosphere 6, 1359-1368 (2012).

\section{Acknowledgements}

16 The author acknowledges the support provided through the Grantham Chair in

17 Climate Science at the University of Reading. Helpful comments on the manuscript

18 were provided by Sandrine Bony, Isaac Held, Brian Hoskins, Michaela Hegglin, and

19 three anonymous reviewers. 
Figure 1 | Contrast between the robustness of observed changes in

2 thermodynamic and dynamic aspects of climate. a-b, global annual mean surface

3 temperature anomaly, and Arctic summer sea-ice extent. c-d, annual mean Southern

4 Oscillation (ENSO) index derived from surface pressure measurements at Tahiti and

5 Darwin, and All-India Summer Monsoon Rainfall anomaly. See Methods for data

6 sources.
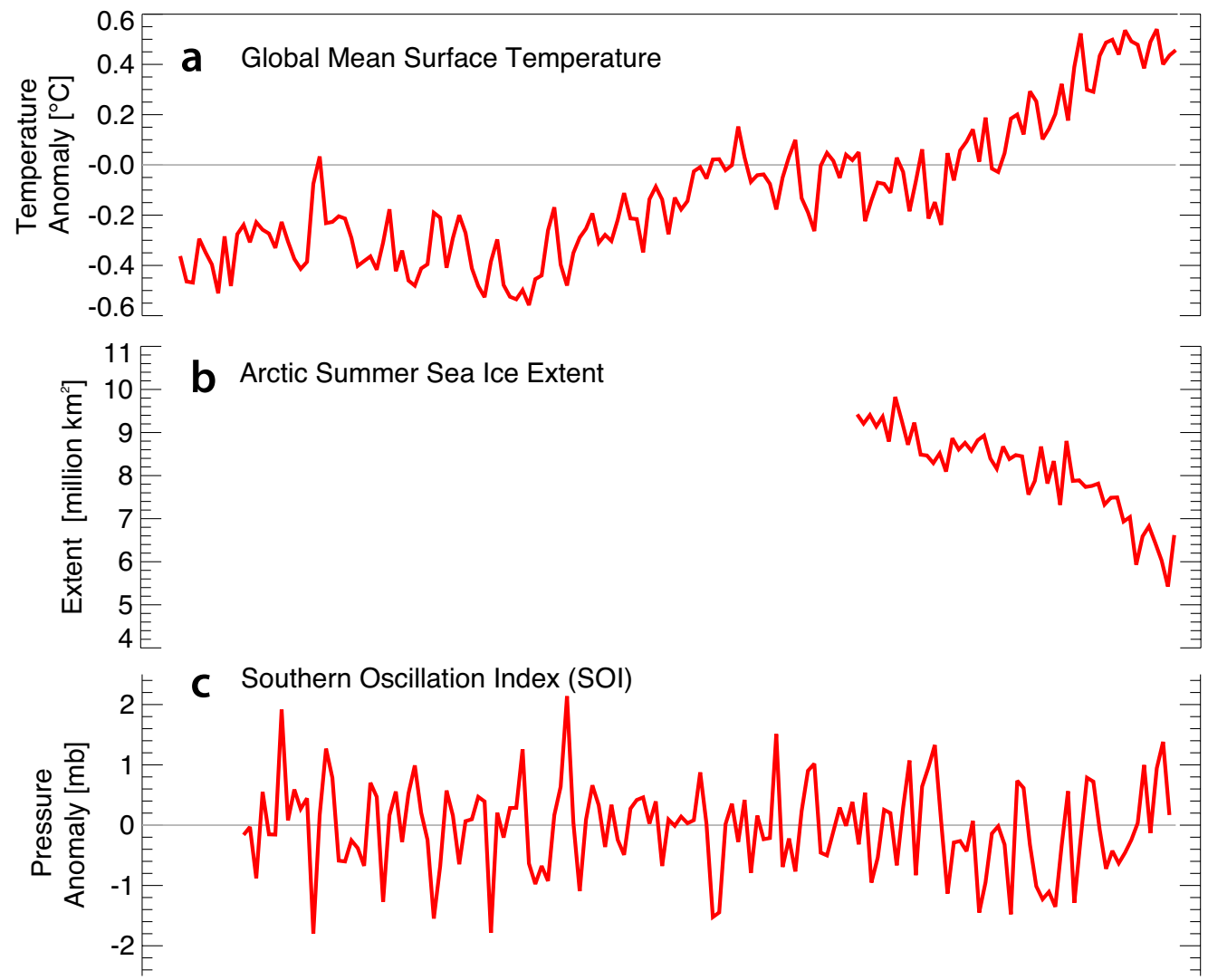

7

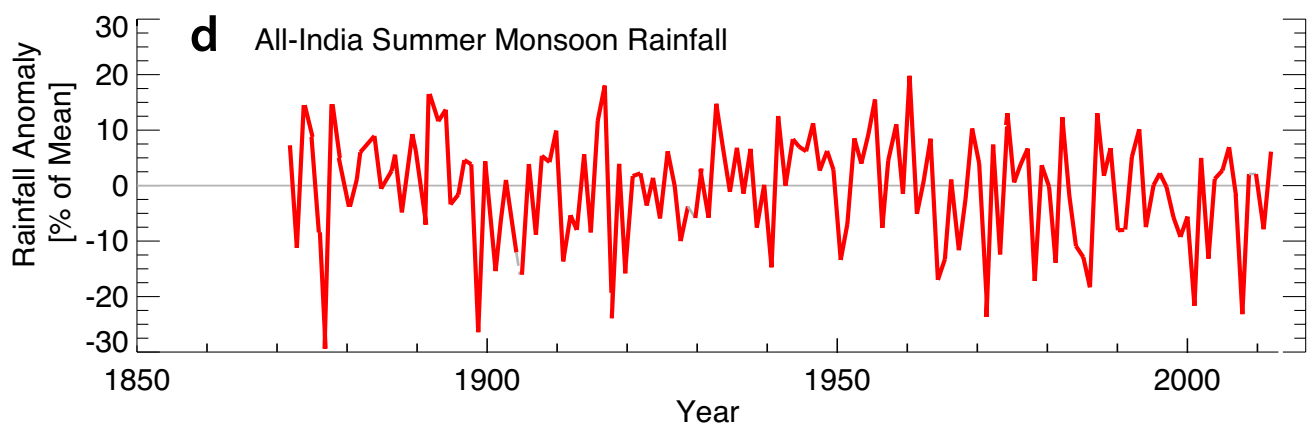

8 
Figure 2 | Contrast between the robustness of projected changes in surface temperature and in precipitation. Mean changes projected over the $21^{\text {st }}$ century by the CMIP5 model ensemble according to the RCP 8.5 scenario in a surface air temperature and $\mathbf{b}$ precipitation. Hatching indicates where the multi-model mean change is small compared to natural internal variability (less than one standard deviation of natural internal variability in 20-year means). Stippling indicates where the multi-model mean change is large compared to natural internal variability (greater than two standard deviations) and where at least $90 \%$ of models agree on the sign of change. Adapted from Figure SPM.8 of Ref. 1.
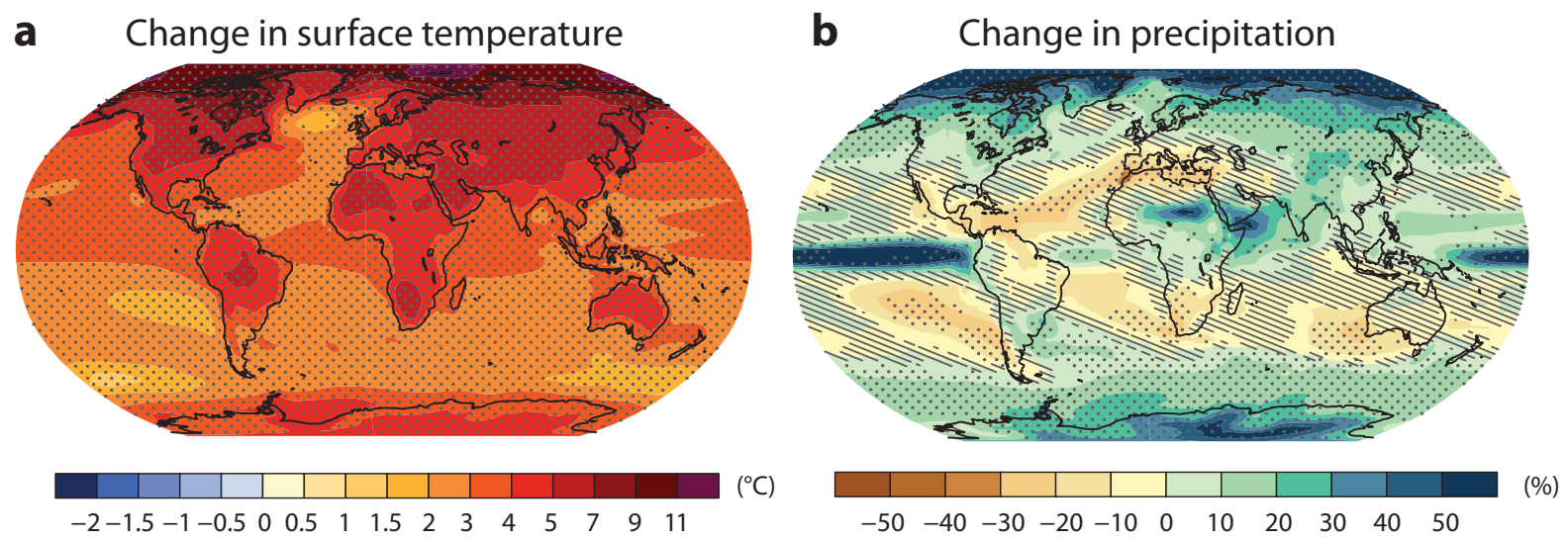

Figure 3 | Impact of natural internal variability on regional aspects of climate change. a-c Histograms of projected wintertime regionally-averaged changes between 2005-2060 over the Eurasian-North Atlantic sector for a sea-level pressure, $\mathbf{b}$ precipitation, and $\mathbf{c}$ surface air temperature, for a control single-model ensemble (gray) and for a single-model ensemble forced by the A1B climate-change scenario (red). The horizontal axis is in units of standard deviation from the control ensemble, and the vertical axis in relative fraction of ensemble members. Adapted from Figure 13 of Ref. 20.
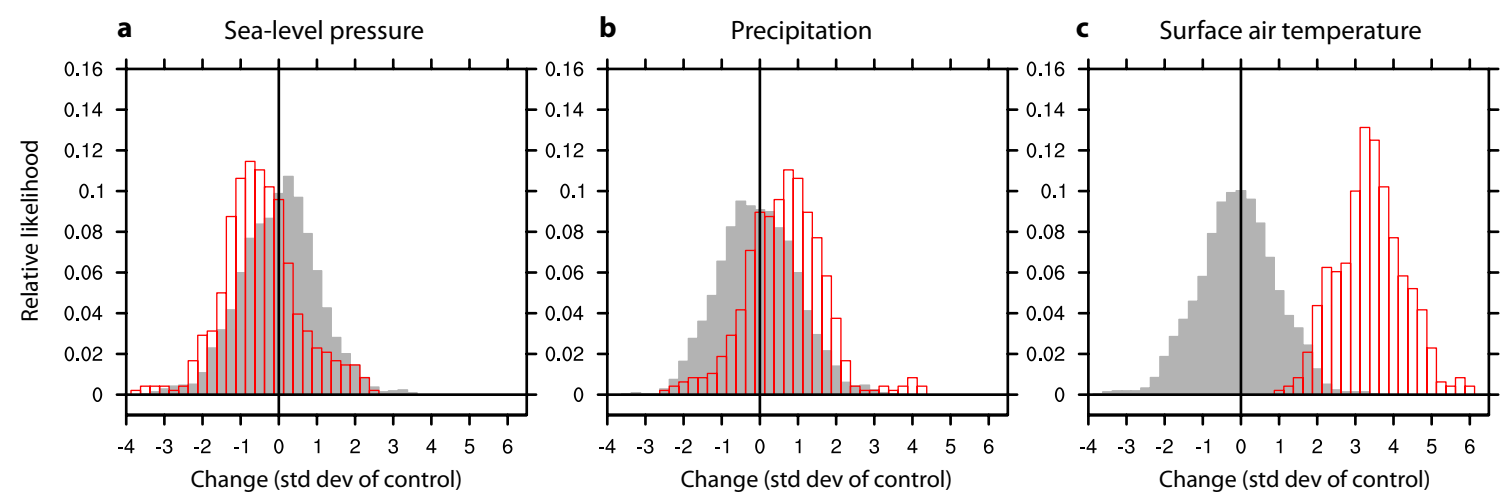
Figure 4 | Non-robustness of predicted circulation response to climate change.

2 Lower tropospheric (850 hPa) wintertime zonal wind speed (gray contours, $5 \mathrm{~m} / \mathrm{s}$

3 spacing) over the North Atlantic, and the predicted response to climate change over

4 the $21^{\text {st }}$ century under the RCP 8.5 scenario (colour shading, units of $\mathrm{m} / \mathrm{s}$ ), from four

5 different CMIP5 models, averaged over five members from each model ensemble

6 (see Methods). Stippling (density is proportional to grid spacing) indicates regions

7 where the climate change response is significant at the $95 \%$ level based on the five

8 ensemble members. Figure provided courtesy of Giuseppe Zappa, University of

9 Reading.
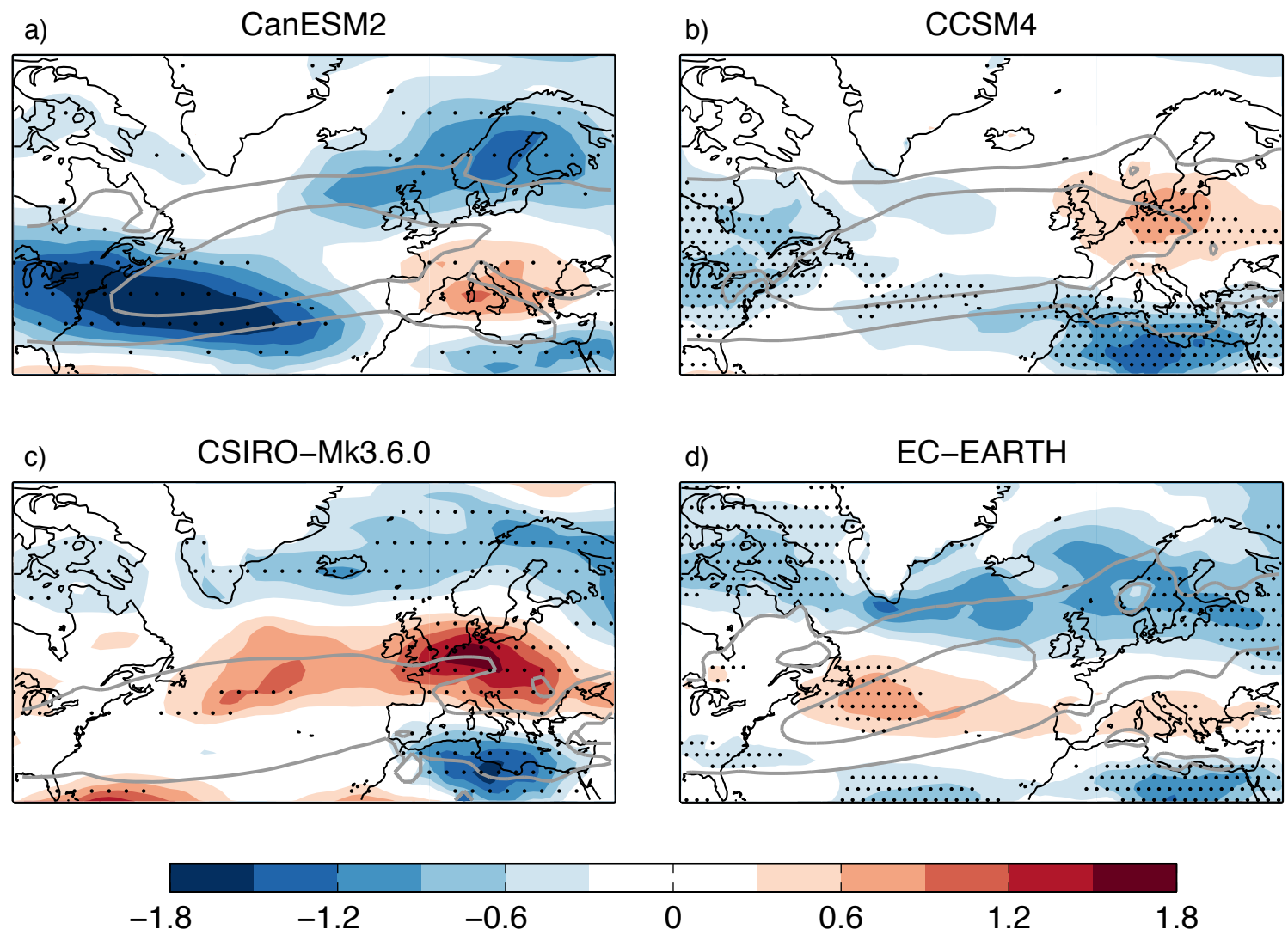